\title{
Evaluation of hypoglycemic properties of kodo millet based food products in healthy subjects
}

\author{
Yadav Neelam ${ }^{2}$, Chaudhary Kanchan ${ }^{1}$, Singh Alka ${ }^{2}$, Gupta Alka ${ }^{1}$ \\ ${ }^{l}$ Department of Foods and Nutrition, Allahabad Agricultural Institute-Deemed University, Allahabad, India. \\ ${ }^{2}$ Centre of Food Technology, Science Faculty Campus, University of Allahabad, Allahabad, India.
}

\begin{abstract}
The glycemic index (GI) of Kodo incorporated (60\%) Idli and Sewai upma and their corresponding control products were determined in ten normal subjects. Using a randomized crossover design the reference and test foods were fed in random order on separate occasions after an overnight fast. Capillary blood samples were collected through finger-prick and analyzed for glucose level by using automatic analyzer at 0, 15, 30, 45, 60, 90 and 120 min interval after consuming reference (glucose) and test food containing $50 \mathrm{~g}$ available carbohydrate. No significant difference was observed between control and Kodo based Idli and Sewai upma in terms of appearance, texture, flavour and taste and overall acceptibility. The incremental area under curve (IAUC), GI and Glycemic Load (GL) values were determined for each test food. The GI of Kodo based Idli (58.53 (SEM 1.48)) and Sewai upma (65.49 (SEM 1.01)) was considerably lower than the control Idli (67.11 (SEM 3.25)) and Sewai upma (69.49 (SEM 1.01)). The correlation between GI-GL $\left(r^{2}=0.999, p \leq 0.01\right)$ and between GI and IAUC $\left(r^{2}=0.994, p \leq 0.01\right)$ was found positive and highly significant. Including these value added products containing kodo millet in daily diet could help a better glucose control and aid in avoiding diabetic complications.
\end{abstract}

\section{Keywords: Glycemic Index, Glycemic load, Incremental area under curve, Diabetes, Value added products}

\section{INTRODUCTION}

Kodo millet (Paspalum scrobiculatum) is one of the hardiest crops grown in Madhya Pradesh, Maharashtra, and Uttar Pradesh and various other parts of India. Minor millets like kodo is also described as nutritious millet and has received far less research and development attention than other crops with regard to crop improvement and utilization. According to Directorate of Millets Development, kodo millet is grown in area of about 907,800 ha with annual production of about 310,710 tonnes. It is the main source of protein and minerals in the daily diets of tribal and weaker section living in remote rural areas [1]. Millets are nutritionally superior than other cereals. The millet contains a high proportion of complex carbohydrate and dietary fiber which helps in prevention of constipation and slow release of glucose to the blood stream. Glycemic index is an important tool used in treating people with diabetes [2,3], cardiovascular disease management [4], and weight regulation programs [5]. Millets including Kodo contain water soluble fiber and this property may be utilized for maintaining or lowering blood glucose response among diabetic and CVD patients. Glycemic load (GL) representing both quality and quantity of carbohydrate in a food and allows comparison of the likely glycemic effect of realistic portion of the different foods.

Low glycemic index foods have been shown to improve the glucose tolerance in both healthy and diabetic subjects [6]. Therefore in the present study kodo millet a locally available, unexploited food was selected in order to develop low glycemic index food and to produce data that can effectively enable the use of GI for dietary recommendations. In present study we compared the Glycemic index of control Idli and Sewai upma with the newly developed kodo millet based products.

\section{MATERIALS AND METHODS}

\subsection{Procurement of raw materials}

Kodo millet was procured from the local farmers of Chunar village of Mirzapur district of Uttar Pradesh (U.P.), India. 


\subsection{Nutritional and chemical composition of kodo millet}

All determinations were done by following the AOAC (1980) official protocols [7]. The Soxhlet method was used for total fat determination. Crude fiber was obtained after samples digestion with diluted acid and alkali. Moisture was determined from sample weight loss after drying at $110^{\circ} \mathrm{C}$ for $4 \mathrm{~h}$. Protein content was determined by Lowry's method [8] and Carbohydrate by difference method. Calcium was determined by titration method and Iron by Spectrophotometric method. All samples were analyzed in triplicate.

\subsection{Development of Kodo millet based products}

Two recipes Idli and Sewai upma were standardized and served as control $\left(\mathrm{T}_{0}\right)$. Idli is a fermented and steamed product of rice and splitted black gram, consumed as a staple food in the Southern part of India. Sewai upma is an extruded-traditional food of Indian diet made up of refined wheat flour. In both the products the main ingredients i.e. rice in Idli and extruded refined flour in Upma was replaced with $20 \%\left(\mathrm{~T}_{1}\right), 40 \%\left(\mathrm{~T}_{2}\right)$ and $60 \%\left(\mathrm{~T}_{3}\right)$ of Kodo millets. Sensory evaluation of the control and all the treatments was done with the help of nine point hedonic scale by a panel of seven judges.

\subsection{Study Protocol}

\subsubsection{Participant characteristics}

Ten normal weight female volunteers aged between 20 to 25 year were recruited from the students of Allahabad Agriculture Institute-Deemed University. They were clinically normal and non diabetic. Subjects were excluded if they were on any special diet, had a family history of diabetes or were on any medication. The subjects were apprised about the experiment and their consent was taken. The present study was conducted according to the guidelines laid down in the Declaration of Helsinki, and all procedure involving human subjects were also approved by the Ethical Committee of the Allahabad Agricultural Institute-Deemed University, Allahabad.

\subsubsection{Analysis of blood glucose in the subjects}

All subjects for investigation fasted overnight (10-12 h). Their blood samples were collected through finger prick using a hypodermic needle or lancets. Each blood sample was inserted into a calibrated glucometer (ACCU CHEK-Active/ one touch) which gave direct reading after 45 seconds based on glucose oxidase assay method [9]. The determination of blood sugar was taken at different intervals i.e.0 (fasting) min, 15, 30, 45, 60, 90 and 120 min after feeding the experimental diets to the subjects.

\subsection{Experimental diets}

\subsubsection{Reference foods}

After fasting for 10-12 h, subjects were required to arrive at the laboratory at $8 \mathrm{O}$ ' clock in the morning and blood samples were obtained. Fasting blood sugar was estimated and postprandial blood sugar was taken at $15,30,45,60,90$ and $120 \mathrm{~min}$ interval after consumption of $50 \mathrm{~g}$ glucose dissolved in $200 \mathrm{ml}$ drinking water.

\subsubsection{Test foods}

Two preparations namely Idli and Sewai upma standardized in the Nutrition lab were used as test foods I. Idli and Sewai upma developed by incorporating kodo millets at 60 percent levels were taken as a test food II as they scored best in terms of organoleptic characteristics. Description of the test foods is shown in Table 1. Fifty g of available carbohydrate (Total carbohydrate minus dietary fiber) for each test food sample was calculated from the results of the proximate analysis and the measured portion of the food was served to the subjects. Fasting blood glucose samples of the subjects after 10-12 $\mathrm{h}$ of overnight fasting was obtained, whereas PPBS was taken at 15, 30, 45, 60, 90 and 120 min intervals after the consumption of test foods II.

\subsection{Computation of Glycemic Index (GI) and Glycemic Load (GL)}

Changes in blood glucose concentration were calculated separately for each post meal period by using the blood concentration before meal (time 0 ) as a baseline. Postprandial responses were compared for maximum increase and incremental area under the glucose curves for each food. The protocol used was adapted from that described by Wolever et al. [10] and is in line with the procedures recommended by the Food and Agriculture Organization / World Health Organization [11].

Glycemic index was calculated by using the following formula:

$$
\mathrm{GI}=\frac{\text { IAUC for test food }}{\text { Mean IAUC for reference food }}
$$


Calculation of Glycemic load: The GL of a specific serving of each food was calculated using the following equation [12]:

$$
\mathrm{GL}=\frac{\text { Glycemic Index of food }}{100} \times \text { carbohydrate eaten }(\mathrm{g})
$$

\subsection{Statistical analysis}

Analysis of variance and significant difference among means were tested by one way ANOVA using SPSS software (version 12.0). Significant difference between the treatments was determined by using critical difference test and t- test was applied to find the difference in the IAUC values and GI of the control and developed products.

To examine the correlation between the GI- GL and GI and IAUC Pearson's correlation coefficient was used. Levels of inter- individual variation of standard (glucose) was assessed by determining the coefficient of variance $(\mathrm{CV}=100 \times \mathrm{SD} /$ mean value $)$.

\section{RESULTS}

Nutritive value of Kodo millet obtained is compared with the values reported by ICMR and FAO [13] and is presented in Table 2. In comparison to other commonly consumed cereals in India, the value of crude fiber $(8.5 \mathrm{~g} / 100 \mathrm{~g})$ and iron $(2.9 \mathrm{mg} / 100 \mathrm{~g})$ was found to be higher in Kodo millet. The value of most nutrients are comparable to ICMR value, however the value of protein, fat and ash reported by FAO are higher in comparison to present study.

Sensory characteristics of the products (Table 3) showed that Idli prepared by kodo millet incorporating 20 per cent (T1), 40 per cent (T2) and 60 per cent (T3) of millets was found acceptable for color, flavour and taste, texture and over all acceptability and there was no significant difference between control and all treatments. Sensory score of Sewai upma prepared by incorporating kodo millet at 20 per cent (T1), 40 per cent (T2) and 60 per cent (T3) of flour showed that treatment $\mathrm{T}_{3}$ was best for flavour and taste, whereas there was no significant difference between color, texture and overall acceptability.

Figure 1 and 2 shows the mean blood glucose at different time intervals after consuming the reference food (glucose) and the test foods. The result showed that Postprandial blood sugar value (PPBS) of reference food ranged between 3.71 to 5.4 and 3.83 to $5.27 \mathrm{mmoL} / \mathrm{L}$. PPBS value was highest for reference food (glucose) followed by control Idli and Sewai upma as test food I and kodo based Idli and Sewai upma as test food II respectively. The highest mean blood glucose response for reference food was found at $45 \mathrm{~min}$ interval, whereas for test food it was found at 60 min time interval.

The incremental area under curve which reflect the changes occurring in blood glucose level after consuming test foods was calculated for the blood glucose response over $2 \mathrm{~h}$ period. In this study mean IAUC of kodo based Idli and Sewai upma [404 (SEM 16.83) and 449.36 (SEM 11.98) respectively] were significantly reduced in comparison to their control products [463.35 (SEM 22.12) and 480.55 (SEM 14.57) respectively] (Table 4).

The study reports on glycemic index, IAUC and glycemic load value of control and kodo Idli and Upma is presented in Table 4. Kodo millet based (60\%) Idli and Sewai upma had lower GI i.e. 58.53 (SEM 1.43) and 65.49 (SEM 1.01) respectively in comparison to control Idli and Sewai upma 67.11 (SEM 3.25) and 69.14 (SEM 1.74) respectively as shown in Table 4 . The difference in the glycemic index of kodo based product and control were found highly significant $(\mathrm{p} \leq .01)$. The glycemic load value of Idli and Sewai upma developed by incorporating $60 \%$ of kodo millet were also reduced (28.7 and 32.7 respectively) in comparison to control Idli and Sewai upma (33.5 and 34.5 respectively).In present study the glycemic index of Kodo Idli and Upma was significantly lower than their corresponding Idli and Upma. The relationship between GI-GL $\left(\mathrm{r}^{2}=0.999\right.$, $\mathrm{p} \leq .01)$ and between GI and IAUC $\left(\mathrm{r}^{2}=0.994, \mathrm{p} \leq .01\right)$ was found positive and highly significant.

\section{DISCUSSION}

The data from the present study demonstrates decrease mean glucose level and GI of Idli and Sewai upma when incorporated with kodo millet $(60 \%)$. The CV \% of inter-individual variation in the control Idli and Sewai upma was found to be 4.03 and 4.98 respectively. Similarly the values of GI in the Kodo based products were low ( Kodo Idli 3.98 and Kodo upma 3.53). Smaller CV \% values of mean blood glucose level representing variation between subjects produces a useful statistics for comparing the precision of different variables [14]. The smaller value of CV \% shows that the group of the test subjects was homogenous. Cereals and millets are richest source of carbohydrate and serve as a major source of energy of human being. 
Carbohydrate foods particularly rice and wheat (60-65\%) provide the bulk of energy in Asian Indian diet [15]. Understanding the glycemic response of such staple foods is essential, particularly for insulin resistant people [16].Brand-Miller et al., [2] have documented that glycemic index value can be classified into three main categories: <55 (low GI food), 56-69 (intermediate GI food) and >70 (high GI food). Studies have reported high GI value of white rice (87) [12] and extruded wheat flour products (80) [17], so we can say that traditional Idli (control) which is usually made up of rice and Sewai upma which is made up of refined wheat flour can be classified as high GI food and not recommended for diabetic patients .In the present study control Idli and Sewai upma was replaced with kodo millet $(60 \%)$, which resulted in $15 \%$ and $9 \%$ decline in GI respectively. This would be of great importance in South East Asia, where the diabetes is one of the major health problems, and where the diet usually consists of high carbohydrate cereal based foods $[18,19,20]$.

Crude fiber content in kodo millet $(8.5 \mathrm{~g} / 100 \mathrm{~g})$ was found to be high in comparison to white rice $(0.2$ $\mathrm{mg} / 100 \mathrm{~g})$ and refined wheat flour $(0.3 \mathrm{mg} / 100 \mathrm{~g})$ [21] and this may be possible reason that kodo based products has lower GI in comparison to control with altering the available carbohydrate content. According to Ludwig et al. [22] the glycemic effect of food is influenced by different factors such as presence of dietary fiber, type of carbohydrate, nature of starch granules, physical form of food and processing. In addition to that amylose: amylopectin ratio in starch and alpha -amylase inhibitor lowers the GI of food by slowing starch digestion [23]. Incorporation of high fiber food in various products can reduce the glycemic response of product. Food rich in dietary fiber reduces the postprandial blood glucose response, simply by reducing the rate of absorption of carbohydrate due to the formation of viscous gel in the small intestine. Millets are nutritionally superior to other cereals. Millet contains high proportion of dietary unavailable carbohydrate, beta glucan and soluble sugars that is useful in improving glucose metabolism. Thondre and Henry [24] also found significant reduction in glycemic index of chapatti (Indian unleavened flatbread) when incorporated with 4 and $8 \%$ of the barley beta glucan. The similar study was also conducted by Marangoni and Poli [25] and they concluded that fiber mix added to the flour, used in preparation of biscuits and breads markedly reduced their glycemic index. The therapeutic effect of Kodo millet on lowering postprandial blood glucose response is probably due to high viscous soluble fiber which is not hydrolyzed by the digestive enzymes. Soluble fiber results in high viscous intestinal contents with gelling properties that could delay the intestinal absorption [26]. It is not only the GI of the carbohydrate diet that affects glucose and insulin response but also the quantity of carbohydrate consumed. Both these variables are represented by Glycemic load. In the present study the GL of control Idli and Sewai upma was higher than kodo incorporated Idli and Sewai upma. A number of epidemiological studies have correlated the GI and GL to disease risk. The combination of low intake of cereal dietary fiber and high GL was associated with a double risk of women developing diabetes [27, 28] and coronary heart diseases [4].It has been reported that cardiovascular diseases, duodenal ulcer and hyperglycemia occur rarely in regular millet eaters [29].

Kodo millets are rich sources of phenolics, tannin and phytates, which can also act as antioxidants and showed beneficial role in protecting against oxidative stress and maintaining blood glucose response. Whole grain flour of kodo millet showed a greater reduction in blood glucose (42\%) and cholesterol than those fed the finger millet [30]. Addition of kodo millet could be highly effective method for lowering the GI of Idli and Sewai upma which are widely consumed by the people of South Asia and expatriate community of Indian origin living worldwide, however, GI of kodo is not available in the published literature and very limited studies on GI of Idli and Sewai upma are available; therefore the result could not be compared with other studies. This study will be of great help to obese and diabetic people who can include kodo incorporated Idli and Sewai upma in their daily diet. For the better management and prevention of chronic diseases such as type II diabetes and CVD, the United Nations FAO/WHO [11] recommend that the GI foods be used in combination with information about food composition to guide food choices.

\section{CONCLUSION}

In conclusion the present study showed that products developed by incorporating Kodo millets are acceptable and they markedly reduce the GI. Similar result could be expected in other Rice and refined Wheat flour based other foods after substituting these cereals with Kodo millets.

\section{ACKNOWLEDGMENTS}

We are thankful to our student's volunteers who participated in the GI testing study. Our special thanks to Dr. A.R. Kumar, Head, Dept. of Food and Nutrition and other teaching faculties who provided technical guidance for this. 


\section{REFERENCES}

[1]. M.S. Ahmad and H.S. Yadava, Assessment of productive and economics of small millets in Madhya Pradesh. Advances in Plant Sciences, 9, 1996, (11 Suppl : 31-3).

[2]. J.C. Brand-Miller, Metaanalysis of low glycemic index diets in the management of diabetes. Diabetes Care, 26, (12), 2003, 3363-4.

[3]. G. Riccardi, A.A. Rivelluse, and R. Giacco, Role of glycemic index and glycemic load in the healthy state, in prediabetics and in diabetes. American Journal of Clinical Nutrition, 87, (suppl), 2008, 269S-74S.

[4]. S. Liu, W.C Willet, M.J. Stamfer, A prospective study of dietary glycemic load, carbohydrate intake and risk of coronary heart disease in U S women. American Journal of Clinical Nutrition, 71, 2000, 1455-1461.

[5]. D.B. Pawlak, C.B. Ebbelling, D.S. Ludwig, Should obese patients be counselled to follow a low glycemic index diet? Yes. Obesity Reviews, 3, 2002, 235-43.

[6]. D.J.A. Jenkins, T.M.S. Wolever, G. Buckley, Low glycemic index starchy foods in the diabetic diet. American Journal of Clinical Nutrition, 48, 1988, 248-254.

[7]. Official methods of Analysis of the association of official analytical chemistry (AOAC) $1980 \mathbf{1 2}^{\text {th }} \mathrm{ed}$.

[8]. O.H. Lowry, N.J. Rosebrough, A.L. Farr, Protein measurement with the folin phenol reagent. Journal of Biological Chemistry, 193, 1951, 265-275. Pub Med.

[9]. L.C. Clark and C. Lyons, Electrode system for continuous monitoring in cardiovascular surgery. Annals of the New York Academy of Sciences, 102, 1962, 29-45.

[10]. T.M.S. Wolever, D.J.A. Jenkins, A.L. Jenkins, The glycemic index methodology and clinical implications. American Journal of Clinical Nutrition, 54, 1991, 846-854.

[11]. FAO/WHO, Carbohydrate in human nutrition: Report of joint FAO/WHO expert consultation. FAO Food and Nutrition Paper, 66, $1998,1-140$.

[12]. K. Foster-Powell, S.H. Holt, J.C. Brand-Miller, International table of glycemic index and glycemic load values. American Journal of Clinical Nutrition, 76, 2002, 5-55.

[13]. FAO, Sorghum and millets in human nutrition. FAO Food and Nutrition Series, No. 27, 1995, Rome, Itali.

[14]. S.B. Hulley, and S.R. Cummings, Designing Clinical Research: An Epidemiologic Approach. Baltimore MD: Williams and Wilkins, 1988.

[15]. The double burden of malnutrition, Case studies from developing countries. FAO Food and Nutrition Paper. Food and Agricultural Organization of the United Nations Rome, 84, 2006, 99-160.

[16]. V. Mohan, P.S. Sharp, and H.R. Cloke, Serum immunoreactive insulin response to glucose load in Asian Indian and European type 2 (non insulin dependent) diabetic patients and control subjects. Diabetologia, 29, 1986, 235-237.

[17]. J.C. Ross Brand, A.W. Thorburn, Glycemic index of processed wheat products. American Journal of Clinical Nutrition, 46, 1987, $631-5$.

[18]. V. Mohan, M. Deepa, R. Deepa, Secular trends in the prevalence of diabetes and impaired glucose tolerance in Urban Rural Epidemiological study.(CURES-17). Diabetologia, 49, 2006, 1175-1178.

[19]. N. Unwin, D. Whiting, D. Gan, In Diabetes Atlas. $4^{\text {th }}$ ed. Belgium: International Diabetes Federation.pp.12, 2009.

[20]. G. Radhika, R. Van Dam, V. Sudha, Refined grain consumption and the metabolic syndrome in Urban Asian Indians[CURES-57]. Metabolism, 58, 2009, 675-681.

[21]. C. Gopalan, B.V. Rama Sastri, S.C. Balasubhramanium, Proximate value of Indian foods. Narsinga Rao BS, Pant KC, Deosthala YG (eds). NIN, Hyderabad India p:47, 2002.

[22]. D.S. Ludwig, J.A. Majzoub, A. Al-Zahrani, G.E. Dallal, I. Blanco, and S.B. Roberts, High Glycemic Index Foods, Overeating and Obesity. Pediatrics, 103, 1999, 1-6.

[23]. L.S. Augustin, S. Franceshi, D.J.A. Jenkins, Glycemic index in chronic disease: a review. European Journal of Clinical Nutrition, 56, 2002, 1049-1079.

[24]. S.P. Thondre, and K.J.C. Henry, High molecular weight barley beta glucan in chapattis (unleavened Indian flatbread) lowers glycemic index. Nutrition Research, 29, 2009, 480-486.

[25]. F. Marangoni, and A. Poli, The glycemic index of bread and biscuits is markedly reduced by the addition of a proprietary fiber mixture to the ingredients. Natural Medicines of Comprehensive Database, 18, 2008, 602-605.

[26]. D.J.A. Jenkins, M.J. Jenkins, T.M.S. Wolever, Slow release carbohydrate: mechanism of action of viscous fibers. Journal of Clinical Nutrition and Gastroenterology, 1, 1986, 237-241.

[27]. F.B. Hu, J.E. Manson, M.J. Stampfer, Diet, life style and risk of type 2 diabetes mellitus in women. New England Journal of Medicine, 345, 2001,790-7.

[28]. J. Salmeron, J.E. Manson, M.J. Stampfer, Dietary fiber, glycemic load and risk of non-insulin dependent diabetes mellitus in women. Journal of American Medical Association, 277,1997, 472-7.

[29]. P. Vijaylakshmi, and R. Radha, Effect of little millet supplementation on Hyperlipidemia. Indian Journal of Nutrition and Dietetics, 44, 2006, 469-474.

[30]. P.S. Hedge, N.S. Rajasekaran, and T.S. Chandra, Effect of the antioxidant properties of millet species on oxidative stress and glycemic status in alloxan - induced rates. Nutrition Research, 25 (12), 2005, 1109-1120.

Table 1. Ingredients (g) and weight of control and developed test foods containing $50 \mathrm{~g}$ available carbohydrate*

\begin{tabular}{lcccc}
\hline Test Foods & $\begin{array}{c}\text { Control Idli } \\
\text { (Test food I) }\end{array}$ & $\begin{array}{c}\text { Kodo Idli } \\
\text { (Test food II) }\end{array}$ & $\begin{array}{c}\text { Control Sewai upma } \\
\text { (Test food I) }\end{array}$ & $\begin{array}{c}\text { Kodo Sewai upma } \\
\text { (Test food II) }\end{array}$ \\
\hline Rice (g) & 45 & 18.4 & - & - \\
Splitted Black & 25 & 30 & - & - \\
gram (g) & - & 27.6 & - & 39 \\
Kodo millet(g) & - & - & 62 & 26 \\
Refined wheat & - & - & 25 & 25 \\
flour (g) & - & - & 25 & 25 \\
Carrot (g) & - & - & 25 & 25 \\
Capsicum (g) & - & - & 10 & 10 \\
Tomato (g) & 70 & 76 & 147 & 150 \\
Refined oil (g) & & & & \\
\hline Weight of one serving(g) & & & & \\
\hline
\end{tabular}

*Available carbohydrate value on dry weight basis. 
Table 2. Nutritional composition of kodo millet

\begin{tabular}{lcccc}
\hline Component & Mean & SEM & ICMR & FAO \\
\hline Moisture $(\%)$ & 7.3 & 0.18 & 12.8 & -- \\
Ash $(\mathrm{g} / 100 \mathrm{~g})$ & 2.6 & 0.21 & 2.6 & 3.3 \\
Crude fiber $(\mathrm{g} / 100 \mathrm{~g})$ & 8.5 & 0.54 & 9.0 & 5.5 \\
Fat $(\mathrm{g} / 100 \mathrm{~g})$ & 1.29 & 0.23 & 1.4 & 3.6 \\
Protein $(\mathrm{g} / 100 \mathrm{~g})$ & 8.03 & 0.13 & 8.3 & 9.8 \\
Carbohydrate $(\mathrm{g} / 100 \mathrm{~g})$ & 64.9 & 1.17 & 65.9 & 66.6 \\
Energy $(\mathrm{kJ} / 100 \mathrm{~g})$ & 1257 & 3.18 & 1282 & 1402 \\
Iron $(\mathrm{mg} / 100 \mathrm{~g})$ & 2.9 & 0.02 & 0.5 & 3.6 \\
Calcium $(\mathrm{mg} / 100 \mathrm{~g})$ & 21.7 & 0.5 & 27 & 31 \\
\hline
\end{tabular}

Table 3. Mean acceptibility scores for control and kodo millet incorporated Idli and Sewai upma:

\begin{tabular}{|c|c|c|c|c|c|c|c|c|}
\hline \multirow[t]{2}{*}{ Recipe/Variation } & \multicolumn{2}{|c|}{ Colour } & \multicolumn{2}{|c|}{ Texture } & \multicolumn{2}{|c|}{ Flavour / Taste } & \multicolumn{2}{|c|}{ Overall acceptibility } \\
\hline & Mean & SEM & Mean & SEM & Mean & SEM & Mean & SEM \\
\hline \multicolumn{9}{|l|}{ Idli : } \\
\hline $\mathrm{T}_{0}$ (Control) & 7.9 & 0.18 & 8.0 & 0.19 & 8.1 & 0.53 & 7.9 & 0.53 \\
\hline $\mathrm{T}_{1}(20 \%)$ & 7.9 & 0.19 & 8.0 & 0.19 & 8.4 & 0.36 & 8.6 & 0.26 \\
\hline $\mathrm{T}_{2}(40 \%)$ & 8.4 & 0.17 & 8.45 & 0.17 & 8.2 & 0.19 & 8.2 & 0.19 \\
\hline $\mathrm{T}_{3}(60 \%)$ & 8.5 & 0.22 & 8.3 & 0.16 & 8.6 & 0.18 & 8.1 & 0.30 \\
\hline \multicolumn{9}{|l|}{ Sewai upma: } \\
\hline $\mathrm{T}_{0}($ Control $)$ & 7.8 & 0.18 & 8.1 & 0.52 & 8.4 & $0.25^{\mathrm{a}}$ & 8.4 & 0.25 \\
\hline $\mathrm{T}_{1}(20 \%)$ & 8.2 & 0.21 & 8.2 & 0.19 & 8.6 & $0.76^{\text {ba }}$ & 8.5 & 0.19 \\
\hline $\mathrm{T}_{2}(40 \%)$ & 8.1 & 0.22 & 8.0 & 0.47 & 8.5 & $0.19^{\mathrm{ac}}$ & 8.6 & 0.25 \\
\hline $\mathrm{T}_{3}(60 \%)$ & 8.4 & 0.52 & 8.4 & 0.2 & 8.7 & $0.44^{\mathbf{b a}}$ & 8.8 & 0.55 \\
\hline
\end{tabular}

Note: Similar alphabets on value denotes non-significant differences, $C D=0.19$

Table 4. Mean incremental area under curve (IAUC), Mean glycemic index and glycemic load of control and developed products prepared by kodo millet

\begin{tabular}{|c|c|c|c|c|c|}
\hline \multirow[t]{2}{*}{ Test foods } & \multicolumn{2}{|c|}{ IAUC } & \multicolumn{2}{|c|}{ GI } & \multirow[t]{2}{*}{ GL } \\
\hline & Mean & SEM & Mean & SEM & \\
\hline Control Idli & 463.35 & 22.12 & 67.11 & 3.25 & 33.55 \\
\hline Kodo based Idli & $404.68 *$ & 16.83 & $58.53 *$ & 1.48 & 28.76 \\
\hline Control Sewai upma & 480.55 & 14.57 & 69.10 & 1.74 & 34.55 \\
\hline Kodo Sewai upma & $449.36 *$ & 11.98 & $65.49 *$ & 1.01 & 32.7 \\
\hline
\end{tabular}

$* P$ value $(<.01)$ refers to difference in IAUC and GI values of control and Kodo based Idli and Sewai upma.

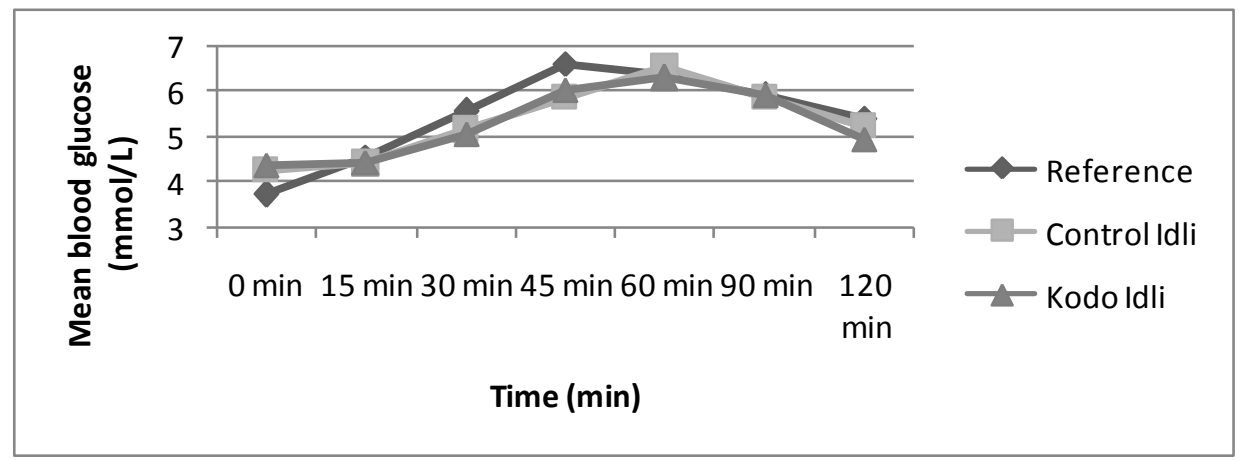

Fig.1. Graphical representation showing the mean blood glucose concentration of the reference (glucose) ( $)$, Control Idli $(\square)$ and Kodo Idli ( $\Delta$ ). 


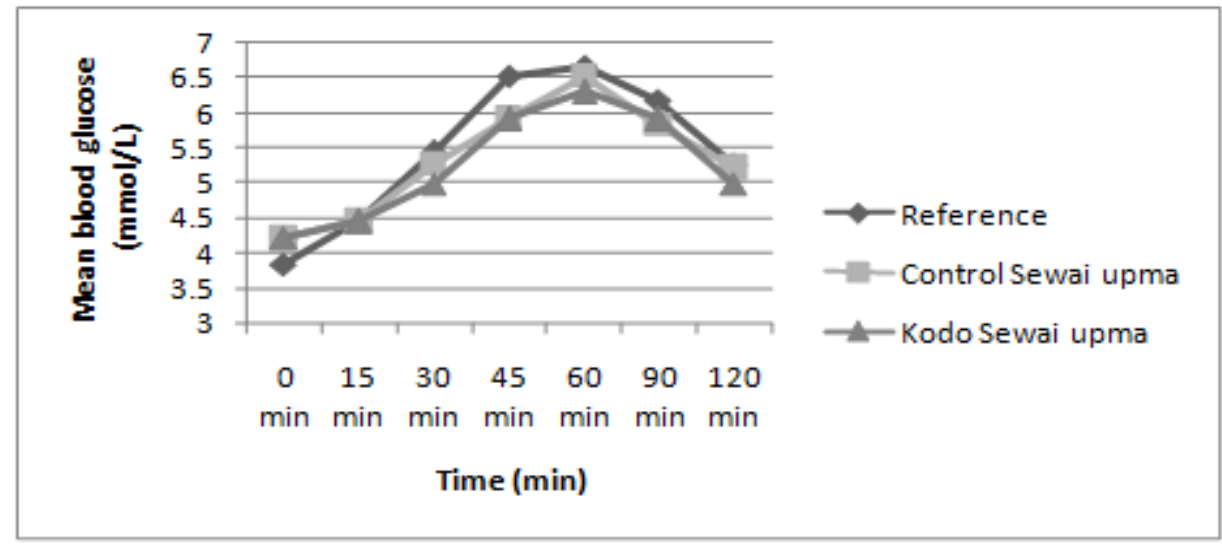

Fig.2. Graphical representation showing the mean blood glucose concentration of the reference food (glucose) $(\triangleleft)$, Control Sewai upma ( $\square$ ) and Kodo Sewai upma (४ ).

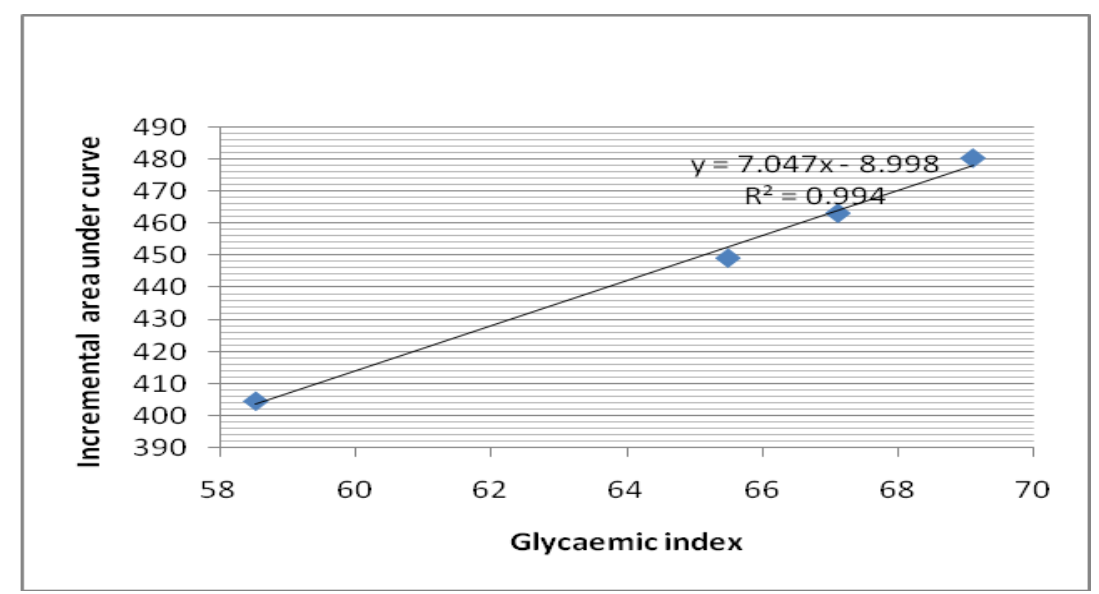

Fig.3. Graphical presentation of correlation between glycemic index and IAUC of control and kodo based Idli and Upma.

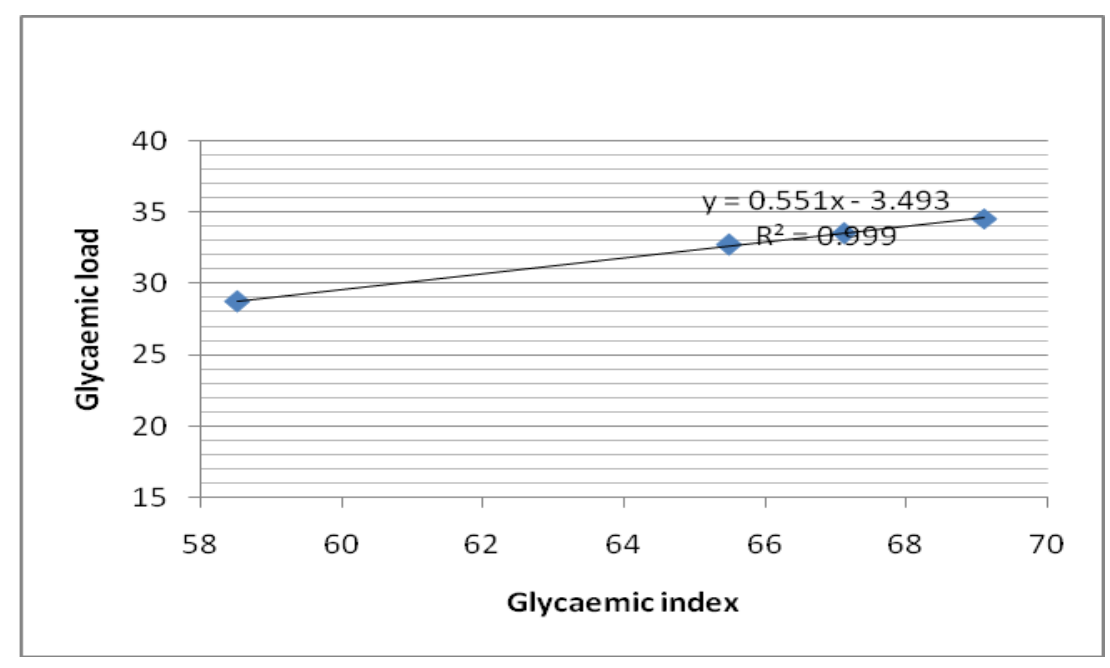

Fig.4. Graphical presentation of correlation between glycemic index and glycemic load values of control and kodo based Idli and Upma. 